\title{
Commentary
}

\section{Causation and complications}

\author{
M. Felix Freshwater
}

Department of Surgery, University of Miami School of Medicine, 9100 S. Dadeland Blvd. Suite 502, Miami FL 33156-7815 USA

Address for correspondence: Dr. M. Felix Freshwater, University of Miami School of Medicine, 9100 S. Dadeland Blvd. Suite 502, Miami FL 33156-7815 USA. E-mail: mfelix.freshwater@gmail.com

hese are the facts that the authors presented: 1.The patient developed his infection eight weeks after his injections.

2. Despite having an infection that required drainage, the patient had normal range of motion in his metacarpophalangeal joints.

3. The patient refused to be admitted to hospital for "surgical drainage under general anesthesia", hence, "less thorough surgical debridement under Bier's block, in the emergency room, was performed."

4. The extensor tendons were found to be intact at that time.

5. Two days later the patient was revaluated and claimed a one-day history of loss of full extension. On examination his active metacarpophalangeal joint motion was only $-30^{\circ} / 90^{\circ}$.

6. Additional surgery was performed that confirmed the rupture of the extensors to the index, long, and ring digits.

7. One week later tendon grafting was performed.

8. One year later the patient's metacarpophalangeal joint motion was $-25^{\circ} / 90^{\circ}$.

The authors claim that this is a "case of rapidly progressive suppurative extensor tenosynovitis, with tendon rupture, following improper administration of local steroids".

By the authors' own admission, the infection occurred eight weeks after the steroid injections. Eight weeks is a rather long time from alleged bacterial inoculation to clinical infection. Furthermore, when the patient was first examined by the authors he had no tendon ruptures and had normal extension. Using a Bier block for anesthesia, they operated under substandard conditions. The patient lost extension within a day. One week later they attempted to reconstruct his extensors, but the final measurements of digital motion were practically the same as immediately after the rupture.

Is the authors' claim valid? Were the tendon ruptures caused by "improper administration of local steroids" or were they caused by something else? More importantly, is there any sound scientific evidence that the steroid injections resulted in the patient's final result?

Stating that a treatment is 'improper' implies that the authors are giving a legal opinion that a malpractice has occurred. Hence, it is worthwhile to consider legal approaches to the causation. The concept of 'proximate cause' is used in the United States and is similar to causation under English Law. ${ }^{[1,2]}$ Both legal systems require that there be a direct link between the alleged cause and the result. In this case that has not been proven. I have injected several liters of steroids into patients' tendon sheaths and joints over the course of my career, and evaluated hundreds of patients who have had injections elsewhere, and although I have seen some tendon ruptures in rheumatoid disease, I have never seen an infection eight weeks after an injection. Perhaps this patient had some unrecognized minor trauma after his injections, but shortly before he arrived under the authors' care?

The authors used a Bier block for their first procedure. Several editions of Greene's Operative Surgery state, 'In the setting of an acute infection, exsanguination with an elastic wrapping is contraindicated, owing to the increased likelihood of bacteremia., ${ }^{[3]}$ Did the authors make a bad situation worse? After, all the tendons ruptured after their first operation and not when they first saw the patient. Perhaps their Bier block caused the infection to damage the extensors? 
The authors performed their tendon reconstructions one week after their second operation. The wounds were still open and the soft tissues were indurated. This violates the principle of tissue equilibrium that has been the hallmark of tendon reconstruction since Steidler coined that term almost a century ago. ${ }^{[4]}$ It is no wonder that the authors' surgical results are for all purposes the same as their preoperative findings, when one considers inter-observer and intra-observer variability. Perhaps the patient would have had a better surgical result if the authors had waited until the wounds had healed and softened?

What lessons can be learned from this case report? Rather than accuse the original treating physician of 'improper' care, the lesson to be learned is an ancient one from the New Testament: "He that is without sin among you, let him first cast a stone." ${ }^{[5]}$

\section{REFERENCES}

1. Available from: http://en.wikipedia.org/wiki/Proximate_cause [last cited on 24 May 2010].

2. Available from: http://en.wikipedia.org/wiki/Causation_in_ English_law [last cited on 24 May 2010].

3. Stevanovic M, Sharpe F. Acute Infections in the Hand. In Green DP, Hotchkiss R, Pederson WS, Wolfe S, editors. Green's Operative Hand Surgery. 5th ed. New York: Churchill Livingstone; 2005. p. 55-6.

4. Available from: http://emedicine.medscape.com/article/1245758overview [last cited on 24 May 2010].

5. Available from: http://www.biblegateway.com/passage/?search= John+8\%3A7\&version=KJV [last cited on 24 May 2010]. 